ORIGINAL RESEARCH PAPER

\title{
FOAM STABILITY OF CLOUDY CARROT JUICE: EFFECTS OF PROTEIN SOURCES AND FOAMING CONDITIONS
}

\author{
HULYA CAKMAK ${ }^{*}$, VASFIYE HAZAL OZYURT ${ }^{2}$ \\ ${ }^{1 *}$ Hitit University, Department of Food Engineering, Corum 19030, Turkey \\ ${ }^{2}$ Mugla Sitki Kocman University, Department of Gastronomy and Culinary Arts, Mugla 48640, \\ Turkey \\ "corresponding author: hulyacakmak@ hitit.edu.tr
}

Received on 29 January 2021

Revised on 17 March 2021

\begin{abstract}
Carrot is an important crop by containing bioactive compounds such as carotenoids, vitamins and dietary fiber. But the shelf life of fresh carrot is limited due to its moisture content. The aim of this study was to evaluate the effects of using different amounts of egg albumen (EA) and whey protein isolate (WPI) and their interactions on carrot juice foam stability. For this purpose, the experimental design was built by response surface method and employing EA amount (5-10-15\%), WPI amount (0-5-10\%) and whipping time (4-6-8 $\mathrm{min})$ as independent variables, while selecting the density and overrun as foam stability evaluation criteria. Among the tested levels of independent variables, the lowest density $(0.2433 \mathrm{~g} / \mathrm{ml})$ and the highest overrun value (2.3466) was observed for $15 \%$ EA with $10 \%$ of WPI incorporation and the 8 min whipped foam. The levels of EA and/or WPI were found significantly effective on the selected responses $(p<0.05)$, however only the interaction of whipping time with WPI amount had significant effect on density and overrun values. The foam stability improvement with WPI incorporation was confirmed by air bubble diameter distribution analysis, and the lowest average foam diameter with more homogeneous diameter distribution was obtained for $15 \%$ EA+10\% WPI foam.
\end{abstract}

Keywords: carrot juice, foaming stability, foam structure

\section{Introduction}

Foams are the colloidal suspensions which are composed of gas entrapped in a liquid continuous phase (Sadahira et al., 2016). Food foams are generated through mixing of protein including solutions for a short period of time, and stabilizers are generally employed for improving the foam stability (Baniel et al., 1997). Proteins possess hydration/water affinity or surface related functional properties such as foaming, emulsification, film formation, solubility, dispersibility, gelation etc. besides their

https://doi.org/10.35219/foodtechnology.2021.1.03 
nutritional properties (Alais and Linden, 1991; Foegeding and Davis, 2011; Walsh, 2014; Kilian et al., 2020). Proteins are absorbed and subsequently create an interfacial film layer between air and liquid phase which then helps to form and stabilize the foam (Foegeding and Davis, 2011). Depending on the ionization of proteins with their either acidic or basic parts, the electrostatic charge of the interface is altered; thus it improves stability of protein mixture (McClements, 2005; Dickinson, 2017).

Of the many animal-based protein sources, globular milk and egg proteins exhibit excellent foaming capacity, therefore are used in many food formulations, such as ice cream, whipped toppings and other culinary products (Baniel et al., 1997; McClements, 2005; Walsh, 2014; Ustunol, 2015; Çakmak, 2020). The foaming mechanisms of these proteins are different since the egg albumen at lower concentration may form much stable foam than whey proteins, while the whey proteins require longer whipping time compared to egg white proteins for reaching similar overrun values (Pernell et al., 2002; Yang and Foegeding, 2010; Foegeding and Davis, 2011). According to the study of Sadahira et al. (2016), soluble solids in the liquid phase improved the foam stability of egg albumen and pectin including foams by increasing the viscosity of the liquid phase. In contrast, increasing the amount of whey protein isolate incorporated into the foam formulation by presence of surface-active cellulose complexes resulted in comparably lower stability against coalescence (Murray et al., 2011). The effect of protein on the foaming capacity is one of the active investigation areas because of the reasons that are above-mentioned. However, the interaction of egg albumen and whey protein isolate within the fruit juice foam system has not yet been studied.

Carrot (Daucus carota L.), with its high biological activity related to its antioxidant, anticancer, antianaemic, healing and sedative properties, and pleasant taste is one of the major important vegetables not only of Turkey but also of worldwide (Ma et al., 2013; Cozma et al., 2015). It is ranked tenth in terms of their nutritional value among 38 other fruits and vegetables, and seventh for their contribution to nutrition (Alasalvar et al., 2005). Carrot is formed of high amounts of water $(\approx 90 \%)$, carbohydrates $(\approx 5 \%)$, and other components such as vitamins and minerals (Gamboa-Santos et al., 2012). By being rich in carotenoids, which give the characteristic orange color to the vegetable, it also contains $9700 \mu \mathrm{g} \beta$-carotene/100 $\mathrm{g}, 3140 \mu \mathrm{g} \alpha$-carotene/100 g and $220 \mu \mathrm{g}$ lutein/100 g (Stahl and Sies, 1999). Moreover, it is one of the major sources of provitamin A for the human diet (Klein and Rodriguez-Concepcion, 2015) and due to its nutrient composition, it provides many health benefits. The common consumption approaches of carrots are as fresh vegetables; however, different processes, such as freezing, canning or dehydration are applied to extend their shelf life. Especially drying attracts more attention, since it has various alternatives that are continuously improved for protecting the bioactive compounds present in carrots. Such as foam-mat drying method is among the most preferred drying methods by decreasing the drying period, improving product quality and preventing the degradation of polyphenols (Kudra and Ratti, 2006; Sangamithra et al., 2015; Abbasi and Azizpour, 2016; Çakmak, 2020). The critical part of foammat drying method is preparation of stable foam structure which includes the 
appropriate selection of the type and amount of foaming agents and/or stabilizers (Sangamithra et al., 2015; Çakmak, 2020). The foam-mat drying of carrot juice and the foam stability by means of formulation and processing conditions are not yet been studied. Thus this study was focused on the primary and critical step of foammat drying.

In this study, the effects of different protein types (egg albumen and whey protein isolate) on foaming capacity of cloudy carrot juice and the effect of whipping conditions on foam stability were investigated. Besides, the air bubble diameter distribution was evaluated as physical stability criteria from the images of the foams.

\section{Materials and methods}

\section{Materials}

Fresh carrots and whole eggs were purchased from a local market in Corum, Turkey and stored at $4{ }^{\circ} \mathrm{C}$ until analysis. The egg albumen is manually removed from whole fresh eggs immediately before preparation of the foams. Whey protein isolate (Hipro, Isowhey, Istanbul) was purchased from the supplier, and as reported on the label 100 gram of product has following amino acid composition: $4.777 \mathrm{~g}$ alanine, $2.334 \mathrm{~g}$ arginine, $11.222 \mathrm{~g}$ aspartic acid, $3 \mathrm{~g}$ cystine, $16.666 \mathrm{~g}$ glutamic acid, $1.666 \mathrm{~g}$ glycine, $2.222 \mathrm{~g}$ histidine, $5.445 \mathrm{~g}$ isoleucine, $12 \mathrm{~g}$ leucine, $11.222 \mathrm{~g}$ lysine, $2.334 \mathrm{~g}$ methionine, $3.555 \mathrm{~g}$ phenylalanine, $4.445 \mathrm{~g}$ proline, $2.778 \mathrm{~g}$ serine, $4.445 \mathrm{~g}$ threonine, $2.778 \mathrm{~g}$ tryptophan, $3.555 \mathrm{~g}$ tyrosine, $5.556 \mathrm{mg}$ valine.

Chemical reagents, namely $\mathrm{KH}_{2} \mathrm{PO}_{4}$ (Merck KGaA, Germany), $\mathrm{K}_{2} \mathrm{HPO}_{4}$ (Merck KGaA, Germany), acetic acid (Sigma Aldrich, Germany), sodium acetate (Merck KGaA, Germany), synthetic $\beta$-carotene standard (C4582), Folin-Ciocalteau phenol reactive (E9252) and DPPH (2.2-diphenyl-1-picrylhydrazil) (D9132) were supplied from local distributors of Sigma-Aldrich (Germany).

\section{Production of cloudy carrot juice}

Carrots were first washed with tap water, and excess water was drained. Then carrots were peeled and cut into around $4 \mathrm{~cm}$ length. The carrot pieces were fed into juice extractor (Arzum, Multivit AR 1060, Turkey), and pulp was removed from the cloudy carrot juice. In order to achieve the enzyme inactivation, the carrot juice that were filled in glass bottles were heat treated at $95^{\circ} \mathrm{C}$ for $5 \mathrm{~min}$ in a water bath (Wise Bath, WB22, Daihan Scientific, South Korea). Heat treated carrot juice was immediately cooled down to room temperature in an ice bath, then filled into PET bottles which were stored at $-18^{\circ} \mathrm{C}$ in a freezer (Regal, $4542 \mathrm{~A} \mathrm{NF}$, Turkey) for further analysis.

\section{Physicochemical properties of carrot juice}

The moisture content of carrot juice, egg albumen (EA) and whey protein isolate (WPI) were determined by using a drying oven (Memmert, UN55, Germany) according to the standard methods of AOAC (2000). Soluble solid content of carrot juice was measured with an Abbe refractometer according to method 932.12 while $\mathrm{pH}$ of the juice was measured with a $\mathrm{pH}-$ meter (Adwa, AD1000, Hungary) (method no: 981.12). Titratable acidity (method no: 942.15 ) was determined according to the 
standard method (AOAC, 2000). Total carotenoid content, total phenolic content and antioxidant activity of carrot juice were measured according to Rodriguez-Amaya (2001), Singleton and Rossi (1965), and Brand-Williams et al. (1995), respectively.

\section{Zeta potential (ל) measurement}

$1 \%(\mathrm{w} / \mathrm{w})$ WPI solution was prepared with Milli-Q water and mixed for $5 \mathrm{~h}$ with a magnetic stirrer (Wisd, MSH20A, Korea). The WPI solution was kept at $4{ }^{\circ} \mathrm{C}$ overnight for complete hydration of the mixture (Ye et al., 2006). The zeta potential measurements of WPI solution and EA were determined between $\mathrm{pH} 2$ to 9 according to the study of Gumus et al. (2017). The $\mathrm{pH}$ of protein sources was adjusted by mixing them 1:100 (v/v) with buffer solutions and the zeta potentials were measured with a zetasizer (Malvern Nano ZSP, UK).

\section{Experimental design and carrot juice foam preparation}

Carrot juice foams were prepared according to the conditions given in the experimental design which was built with Minitab Vers. 15 (Minitab Inc.) software by employing response surface method and central composite design. The experimental design was consisted of EA amount (5-10-15\%, w/w), WPI amount (0$5-10 \%, \mathrm{w} / \mathrm{w})$ and whipping time (WT) (4-6-8 $\mathrm{min})$ as the independent variables. Besides, the foam density and overrun were selected as the responses of this experimental design. The experimental design was built according to the current literature about food foams including egg albumen or whey proteins (Pernell et al., 2002; Yang and Foegeding, 2011; Balasubramanian et al., 2012). Besides, our preliminary analysis involving the excessive amounts of EA (up to 30\%) for carrot juice foam preparations showed that the foam stability was not improved further than the tested amounts in experimental design.

$160 \mathrm{~g}$ of total carrot juice and protein sources given in Table 1 were first mixed for 30 min with a magnetic stirrer (Wisd, MSH20A, Korea). Then these mixtures were whipped into foams by kitchen blender (Arzum Pasto AR-183, Turkey) at the highest speed for proposed time periods given in experimental design. The foam stability was determined according to foam density and overrun responses and calculated according to equations 1 and 2 (Yang and Foegeding, 2010; Sadahira et al., 2016).

$$
\begin{aligned}
& \text { Foam density }(\mathrm{g} / \mathrm{ml})=\frac{\text { mass of foam }}{\text { volume of foam }} \\
& \text { Overrun }=\frac{(\text { mass of } 100 \mathrm{ml} \text { solution })-(\text { mass of } 100 \mathrm{ml} \text { foam })}{(\text { mass of } 100 \mathrm{ml} \text { foam })}
\end{aligned}
$$

\section{Diameter distribution of air bubbles}

The foam was spread over the glass slide immediately after foam preparation and several images were recorded with the $20 \mathrm{MP}$ camera. Only single spheres were included in counting, and overlapped droplets were excluded. The recorded images were analyzed with ImageJ software, and the diameter distribution plots of air bubbles were drawn by Excel.

\section{Statistical analysis}

Carrot juice foam stability was evaluated according to the experimental design that was built by Minitab Vers. 15 (Minitab Inc.) software using response surface 
method. The results were compared based on the regression analysis and analysis of variance (ANOVA) at 95\% significance level with Minitab software.

\section{Results and discussion}

\section{Physicochemical properties carrot juice and protein sources}

The moisture content of heat-treated cloudy carrot juice was $90.88 \pm 0.05 \%$, and total soluble solid content was $9.81 \pm 0.11^{\circ} \mathrm{Bx}$. The $\mathrm{pH}$ was measured as $6.29 \pm 0.04$ and titratable acidity was found as $0.10 \pm 0.01$ citric acid equivalent $/ 100 \mathrm{~g}$ juice. The moisture content of EA and WPI was found as $88.44 \pm 0.14 \%$ and $8.85 \pm 0.11 \%$, respectively. The moisture content of carrot or carrot juice is given between 88.9$90.0 \%$, whereas soluble solid content is found between 4.65-12.0 ${ }^{\circ} \mathrm{Bx}$. Besides the titratable acidity of carrot changes between $0.2-3.0 \%$ citric acid or malic acid equivalent, while the $\mathrm{pH}$ varies between 4.6-6.2 in the literature (Demir et al., 2007; Liao et al., 2007; Sharma et al., 2009; Schultz et al., 2014; Cozma et al., 2015; Silva et al., 2016; Yilmaz et al., 2019).

The total carotenoid content of heat treated carrot juice was found to be $82.35 \pm 0.42$ $\mu \mathrm{g} / \mathrm{g}$, its antioxidant activity was $62.84 \pm 2.82 \%$, and the total phenolic content was $46.36 \pm 0.21 \mathrm{mg} / \mathrm{g}$. Leja et al. (2013) determined the total phenolic content and antioxidant activity of different carrot species at between $18.7 \pm 1.2$ and $58.6 \pm 2.6$ $\mathrm{mg} / 100 \mathrm{~g}$ wet sample and between $3.5 \% \pm 0.8$ and $13.7 \pm 0.6 \%$, respectively. Nowacka and Wedzik (2016) found that the total carotenoid content of carrot was $76.6 \mu \mathrm{g} / \mathrm{g}$, while Mapelli-Braham et al. (2017) and Courraud et al. (2013) found that the total carotenoid content of carrot juice was $70.1 \pm 12.9$ and $82.82 \mu \mathrm{g} / \mathrm{g}$, respectively. It was stated that total carotenoid content, antioxidant activity, and total phenolic content were directly related to the growing conditions and planting season, genetics and soil type.

\section{Zeta potential}

The zeta potential is a measure of effective surface potential of a droplet suspended in a medium (McClements, 2005), and the proteins may be neutral, positively charged, or negatively charged depending on the $\mathrm{pH}$ of the solution. The proteins precipitate at their isoelectric points, therefore it is critical to determine the surface potential of EA and WPI.

Depending on zeta potential measurements, the isoelectric points of EA and WPI were 4.7 and 4.6, respectively. The results are found in accordance with the literature (Pelegrine and Gasparetto, 2005). Both of the protein sources exhibited negative potentials at the natural $\mathrm{pH}$ of heat treated carrot juice (6.29). As it was stated by $\mathrm{Ye}$ et al. (2006), proteins have negative charges and $\mathrm{pH}$ value plays the major role for determinations of electrostatic interaction and stability. Besides, pectin in cloudy carrot juice which is having negative charge at natural $\mathrm{pH}$ of the juice also need to be taken into account before preparing the foaming solution (Schultz et al., 2014). Therefore, the $\mathrm{pH}$ adjustment was not required due to $\mathrm{pH}$-zeta potential relation of protein sources. Therefore, the $\mathrm{pH}$ adjustment was not performed prior to the foam production. 


\section{Evaluation of carrot juice foam stability}

The foam stability is a measure of how the air phase is dispersed in the liquid continuous phase, and the amount of air that is incorporated in to the foam effects the density and the overrun (Baniel et al., 1997; Yang and Foegeding, 2011; Abbasi and Azizpour, 2016). The lowest density with the highest overrun values corresponds to the highest volume of air is entrapped in the foam structure. The average results of density and overrun responses of carrot juice foams are shown in Table 1.

Table 1. Average results of the responses of experimental design.

\begin{tabular}{cccccc}
\hline Order & $\begin{array}{c}\text { EA } \\
(\%)^{*}\end{array}$ & $\begin{array}{c}\text { WPI } \\
(\%)^{*}\end{array}$ & $\begin{array}{c}\text { Whipping time } \\
(\mathrm{min})\end{array}$ & $\begin{array}{c}\text { Density } \\
(\mathrm{g} / \mathrm{ml})\end{array}$ & Overrun \\
\hline 1 & 15 & 0 & 8 & 0.6916 & 0.5365 \\
2 & 15 & 0 & 4 & 0.6693 & 0.6159 \\
3 & 15 & 10 & 4 & 0.3577 & 1.4354 \\
4 & 5 & 0 & 8 & 0.9193 & 0.0800 \\
5 & 5 & 10 & 4 & 0.4794 & 1.0227 \\
6 & 10 & 5 & 6 & 0.4462 & 1.1767 \\
7 & 5 & 10 & 8 & 0.3733 & 1.4190 \\
8 & 15 & 10 & 8 & 0.3074 & 1.9658 \\
9 & 5 & 0 & 4 & 0.8949 & 0.1064 \\
10 & 10 & 5 & 6 & 0.4935 & 1.2604 \\
11 & 15 & 10 & 4 & 0.3696 & 1.4086 \\
12 & 5 & 10 & 8 & 0.3858 & 1.4284 \\
13 & 10 & 5 & 6 & 0.4342 & 1.2894 \\
14 & 15 & 0 & 4 & 0.6490 & 0.6256 \\
15 & 5 & 0 & 4 & 0.8861 & 0.1059 \\
16 & 10 & 5 & 6 & 0.4219 & 1.3974 \\
17 & 15 & 0 & 8 & 0.6418 & 0.5616 \\
18 & 5 & 10 & 4 & 0.4697 & 1.1351 \\
19 & 15 & 10 & 8 & 0.2433 & 2.3466 \\
20 & 5 & 0 & 8 & 0.9093 & 0.0876 \\
\hline
\end{tabular}

$*_{\mathrm{w}} / \mathrm{w}$ of total carrot juice + protein mixture.

Among the tested formulations and foaming conditions, the foam density was found between $0.24-0.92 \mathrm{~g} / \mathrm{ml}$ and the overrun was between $0.08-2.35$, respectively. In the study of Kudra and Ratti (2006), the ideal foam density was recommended between $0.3-0.6 \mathrm{~g} / \mathrm{ml}$, and most of the experiments fall into this range or even lower values than the given recommendation. Although the foam was generated using different protein sources such as egg white, soy protein isolate, or with the addition of foam stabilizers or other additives (carboxymethyl cellulose, methyl cellulose, maltodextrin etc.) the foam density of tomato juice, musk melon pulp, and sour cherry concentrate were found between $0.43-0.73 \mathrm{~g} / \mathrm{ml}$ (Balasubramanian et al., 2012; Abbasi and Azizpour, 2016; Asokapandian et al., 2016).

The amounts of EA and WPI in carrot juice foams was effective on the density and overrun, since 5\% EA incorporated foams without and WPI addition had higher density and lower overrun values. Besides, the highest stability was observed for the 
foams containing 15\% EA+10\% WPI independent of the whipping time (order 3, 8, 11 and 19). The stability of experiment 19 with respect to the lowest density and the highest overrun value was significantly higher than the rest of the formulations. However, the effects and interactions of tested independent parameters were evaluated by regression analysis.

The regression analysis results of density response and the effects of individual parameters or interaction of the independent variables are shown in Table 2. At 95\% significance level, the constant term, EA and WPI were found to be the significant terms on density response. Also the square of EA amount and the interaction of EA with WPI and interaction of WPI with WT found to be significant terms expressing density with high correlation coefficients $\left(\mathrm{R}^{2}>0.98\right)$. Therefore, those effective terms are used for creating an equation (Eq. 3) that represents the behavior of density by altering the independent variables.

$$
\begin{aligned}
& \text { Density }=1.37852-0.12645 \times E A-0.03803 \times W P I+0.00516 \times E A^{2}+ \\
& 0.00132 E A \times W P I-0.00268 W P I \times W T
\end{aligned}
$$

It is clear that the amount of protein sources were more pronounced effect on increasing the foam stability by reducing the density response.

Table 2. Estimated regression coefficients for density response.

\begin{tabular}{lccc}
\hline Term & Coef & $T$ & $P$ \\
\hline Constant & 1.37852 & 21.508 & 0.000 \\
EA \% & -0.12645 & -11.089 & 0.000 \\
WPI \% & -0.03803 & -8.504 & 0.000 \\
WT & 0.00511 & 0.698 & 0.498 \\
EA \%× EA \% & 0.00516 & 9.654 & 0.000 \\
EA \% $\times$ WPI \% & 0.00132 & 5.518 & 0.000 \\
EA \%× WT & -0.00012 & -0.200 & 0.845 \\
WPI \% $\times$ WT & -0.00268 & -4.489 & 0.001 \\
\hline
\end{tabular}

$\mathrm{S}=0.0239067, \mathrm{PRESS}=0.0176085, \mathrm{R}^{2}=99.23 \%, \mathrm{R}^{2}($ pred $)=98.01 \%, \mathrm{R}^{2}(\operatorname{adj})=98.77 \%$

Results of the variance analysis of density response are given in Table 3. The linear, square and interaction of variables together with the regression analysis itself were significantly effective on density values $(\mathrm{p}<0.05)$. Therefore, the variables presented in the Eq. 3 were found important for the estimation of density response $(\mathrm{p}<0.05)$.

The regression coefficients of estimated overrun response are given Table 4. The constant term, EA\%, the square of EA\%, and the interaction of WPI\% with whipping time found to be significantly effective terms in order to explain the overrun response $(\mathrm{p}<0.05)$. So, these parameters were used to build Eq. 4 to explain the effects of selected parameters on overrun response.

Overrun $=-0.877131+0.304214 \times E A-0.014036 E A^{2}+0.014663 W P I \times W T(4)$

Besides, high correlation coefficients (Adj- $\mathrm{R}^{2}$ ) with the low standard deviation (S) and prediction error sum of squares (PRESS) confirmed how well the model predicted this response. 
Table 3. ANOVA results for density response.

\begin{tabular}{lcccccc}
\hline Source & DF & Seq SS & Adj SS & Adj MS & F & P \\
\hline Regression & 7 & 0.878803 & 0.878803 & 0.125543 & 219.66 & 0.000 \\
$\quad$ Linear & 3 & 0.796591 & 0.130683 & 0.043561 & 76.22 & 0.000 \\
Square & 1 & 0.053267 & 0.053267 & 0.053267 & 93.20 & 0.000 \\
Interaction & 3 & 0.028946 & 0.028946 & 0.009649 & 16.88 & 0.000 \\
Residual error & 12 & 0.006858 & 0.006858 & 0.000572 & & \\
$\quad$ Lack-of-fit & 1 & 0.000132 & 0.000132 & 0.000132 & 0.22 & 0.652 \\
$\quad$ Pure error & 11 & 0.006727 & 0.006727 & 0.000612 & & \\
Total & 19 & 0.885662 & & & & \\
\hline
\end{tabular}

The results of variance analysis for the overrun response are given in Table 5. The regression analysis itself, together with the linear, square and interaction of the tested terms were found significantly effective at $95 \%$ level. Similar to the density response, the parameters in Eq. 4 were critical to express the carrot juice foam stability depending on the ANOVA results.

Table 4. Estimated regression coefficients for overrun response.

\begin{tabular}{lccc}
\hline Term & Coef & $T$ & $P$ \\
\hline Constant & -0.877131 & -2.901 & 0.013 \\
EA \% & 0.304214 & 5.655 & 0.000 \\
WPI \% & 0.025260 & 1.197 & 0.254 \\
WT & -0.054262 & -1.571 & 0.142 \\
EA \%× EA \% & -0.014036 & -5.565 & 0.000 \\
EA \%× WPI \% & 0.000479 & 0.424 & 0.679 \\
EA \% $\times$ WT & 0.004251 & 1.507 & 0.158 \\
WPI \% $\times$ WT & 0.014663 & 5.200 & 0.000 \\
\hline
\end{tabular}

$\mathrm{S}=0.112792, \mathrm{PRESS}=0.448031, \mathrm{R}^{2}=98.04 \%, \mathrm{R}^{2}(\mathrm{pred})=94.25 \%, \mathrm{R}^{2}(\mathrm{adj})=96.90 \%$

Presence of whey protein isolate in carrot juice foams had increased the overrun value, though the egg albumen had pronounced effect on foam stability (Eq.3 and 4). Yang and Foegeding (2010) concluded in their study that, WPI had higher overrun values compared to egg white protein at the same apparent viscosity when they were used individually in the foam mixture. Also the smaller foam bubble diameter was associated with lower overrun values by the authors.

The whipping time of foam formation was not effective on the foam stability when used as individually, although its interaction with WPI was effective on both the density and overrun responses $(\mathrm{p}<0.05)$. This may be due to more homogeneous distribution of whey proteins in the foam or better adsorption of whey proteins at the foam interface. Whipping time found to be effective on the yield stress and resulted in higher fractions of air incorporated into foam especially at the high protein concentrations (Pernell et al., 2002). But different protein sources may respond differently to the whipping time, and egg white proteins are known to be transferring 
rapidly into the liquid-air interface compared to other proteins (Sangamithra et al., 2015).

Table 5. ANOVA results for overrun response.

\begin{tabular}{lcccccc}
\hline Source & DF & Seq SS & Adj SS & Adj MS & F & P \\
\hline Regression & 7 & 7.64007 & 7.64007 & 1.091439 & 85.79 & 0.000 \\
Linear & 3 & 6.87083 & 0.58239 & 0.194131 & 15.26 & 0.000 \\
Square & 1 & 0.39403 & 0.39403 & 0.394033 & 30.97 & 0.000 \\
$\quad$ Interaction & 3 & 0.37521 & 0.37521 & 0.125071 & 9.83 & 0.001 \\
Residual error & 12 & 0.15266 & 0.15266 & 0.012722 & & \\
$\quad$ Lack-of-fit & 1 & 0.04813 & 0.04813 & 0.048125 & 5.06 & 0.046 \\
$\quad$ Pure error & 11 & 0.10454 & 0.10454 & 0.009503 & & \\
Total & 19 & 7.79274 & & & & \\
\hline
\end{tabular}

3D surface plots of model estimated density and overrun responses (Figures 1a and 1b) was created by using the parameters effective on the foam stability.

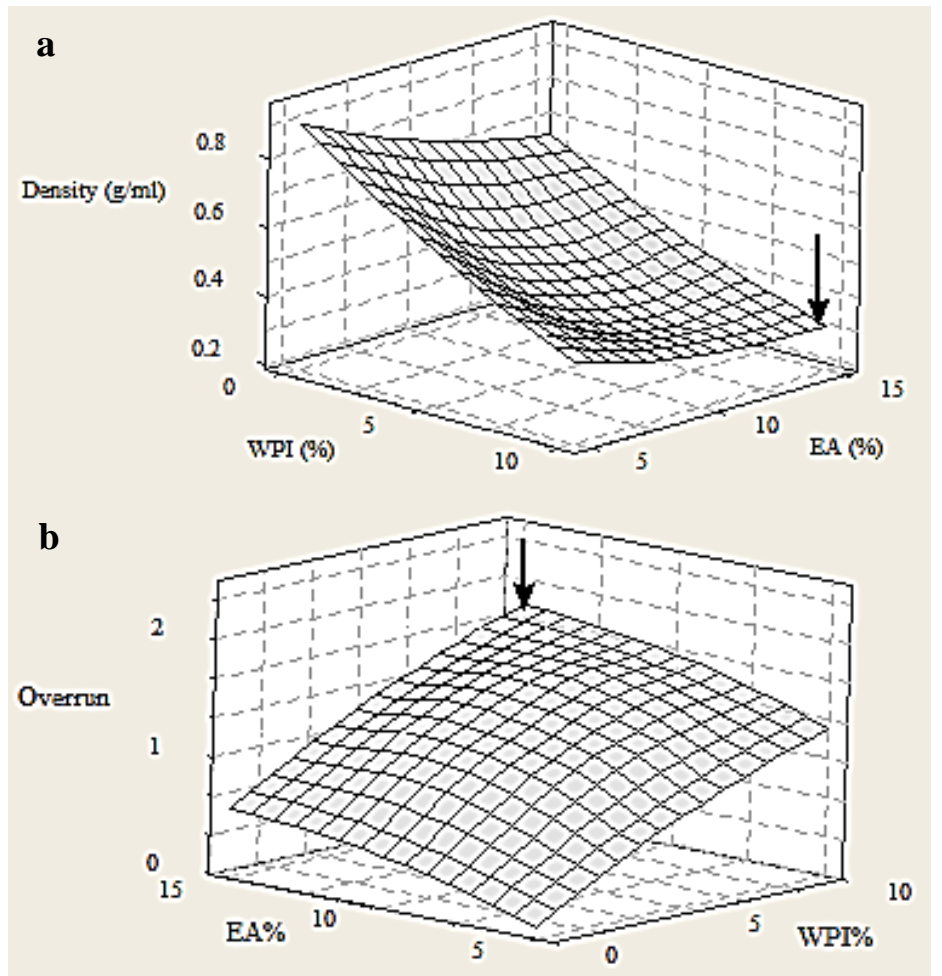

Figure 1.3D surface graphs of predicted density and overrun responses versus EA and WPI contents. 
The foams having maximum stability by means of predicted density and overrun responses were marked with arrows in Figure 1. Similar to the observations given in regression analysis, EA and WPI had a positive impact on foam stability that is the maximizing the amount of protein sources resulted in minimum density and maximum overrun values. The mechanisms of egg albumen and whey proteins are relatively different, since the interfacial elasticity, yield stress and fraction of liquid phase in a protein solution system may affect the foam stability in a great extent (Yang and Foegeding, 2011). Although the EA and WPI were found to be negatively charged, their coexistence in the foam solution possibly created an attractive interaction and strengthened the adsorbed film (Murray et al., 2011).
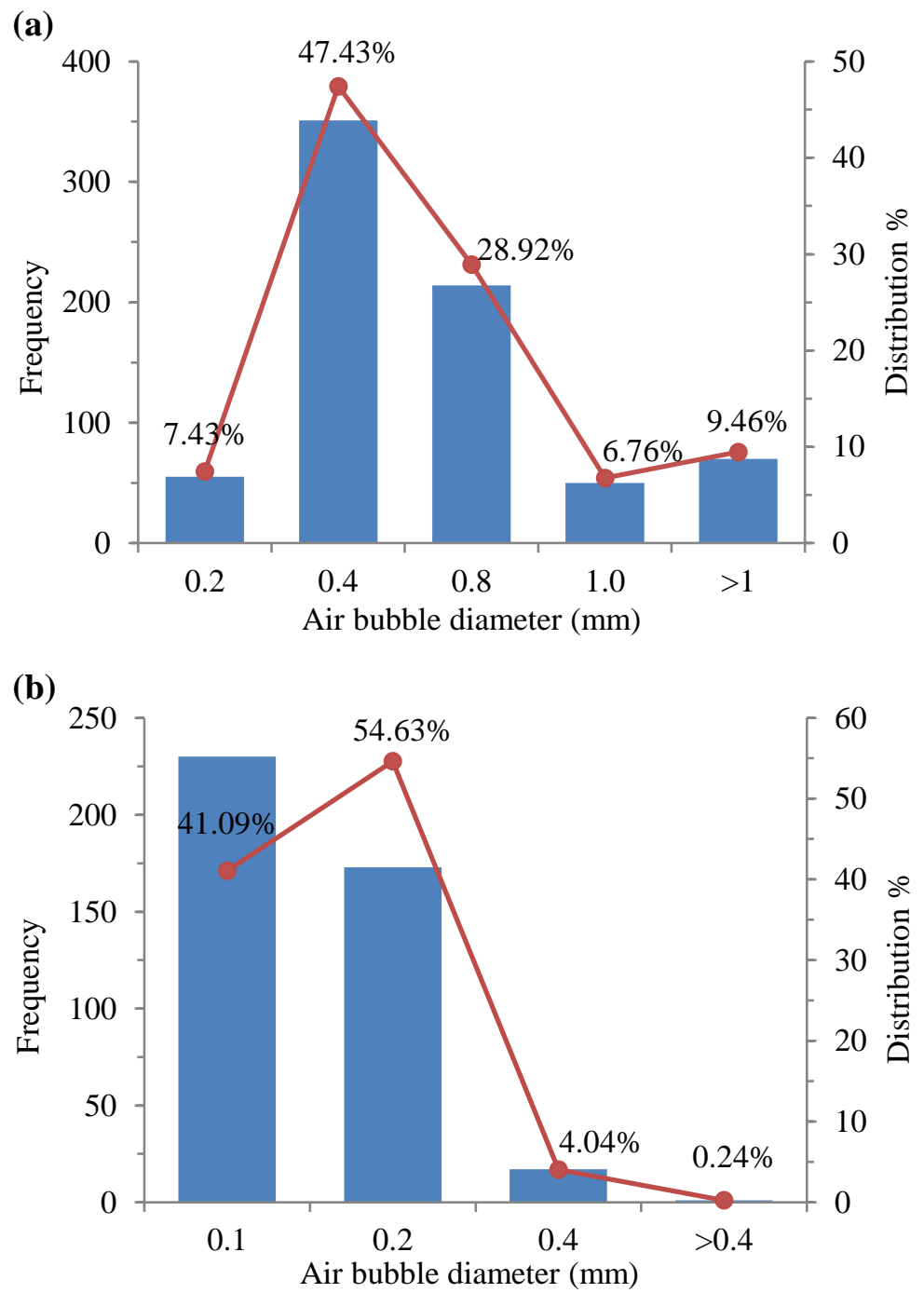

Figure 2. Cumulative bubble diameter distribution of (a): 15\% EA foam, (b): 15\%EA+ 10\% WPI foam. 
The particle diameter distribution of the foams was presented in Figure 2. Depending on the air bubble diameter distribution analysis, $99.8 \%$ of counted bubbles of $15 \%$ EA+ $10 \%$ WPI foam were smaller than $0.4 \mathrm{~mm}$, while $90.5 \%$ of counted bubbles of $15 \%$ EA foam were smaller than $1 \mathrm{~mm}$. As can be seen in this figure, $15 \% \mathrm{EA}+10 \%$ WPI foams had more homogeneous diameter distribution than the 15\% EA foam. This behavior also confirmed by the overrun responses of the carrot juice foams, since the highest overrun values were observed for 15\% EA+ 10\% WPI foams (order 19 in experimental design). Although true sizes of air bubbles may not be calculated due to the changes of number of bubbles while transferring them onto glass slide and shape changes occurred (Pernell et al., 2002), similar conditions were ensured for both of the foams. The presence of WPI together with EA in the carrot juice helped to even distribution of air bubbles inside the foam and improved the foam stability. The effects of egg white proteins and WPI on air bubble diameter are different when they used separately in the foam, since the yield stress, surface tension and air phase fraction of the obtained foams and time dependent destabilization behaviors may vary with respect to protein source (Pernell et al., 2002; Yang and Foegeding, 2011).

\section{Conclusions}

The comparison of different protein sources addition into cloudy carrot juice foam formulations showed that increasing the levels of egg albumen and whey protein isolate resulted in increased foam stability by decreasing the foam density and increasing the overrun. Besides, the whey protein incorporation into carrot juice with EA was even better stability values than using EA alone in the juice. The presence of whey proteins in continuous phase promoted even distribution of air bubbles within the foam structure which was also clearly evident in the diameter distribution plots. Based on the results of this study, bioactive rich vegetable or fruit juices can be used in foam production by employing a mixture of different animal protein sources like egg albumen and whey proteins. The further step of this study will be the production of foam-mat dried carrot juice powders from the foams having the highest stability in order to be used as a functional ingredient in various food compositions.

\section{Acknowledgments}

This study was funded by Hitit University Scientific Research Commission with the project no. MUH19001.18.002. The authors would like to thank Dr. Cansu Ekin Gumus for her help in zeta potential measurements.

\section{References}

Abbasi, E., Azizpour, M. 2016. Evaluation of physicochemical properties of foam mat dried sour cherry powder. LWT-Food Science and Technology, 68, 105-110.

Alais, C., Linden, G. 1991. Food Biochemistry. Springer Science \& Business Media, Dordrecht. 
Alasalvar, C., Al-Farsi, M., Quantick, P.C., Shahidi, F., Wiktorowicz, R. 2005. Effect of chill storage and modified atmosphere packaging (MAP) on antioxidant activity, anthocyanins, carotenoids, phenolics and sensory quality of ready-to-eat shredded orange and purple carrots. Food Chemistry, 89(1), 69-76.

AOAC. 2000. Official methods of analysis of AOAC International. (17th ed.). Gaithersburg, MD, USA.

Asokapandian, S., Venkatachalam, S., Swamy, G.J., Kuppusamy, K. 2016. Optimization of foaming properties and foam mat drying of muskmelon using soy protein. Journal of Food Process Engineering, 39(6), 692-701.

Balasubramanian, S., Paridhi, G., Bosco, J.D., Kadam, D.M. 2012. Optimization of process conditions for the development of tomato foam by box-behnken design. Food and Nutrition Sciences, 3, 925-930.

Baniel, A., Fains, A., Popineau, Y. 1997. Foaming properties of egg albumen with a bubbling apparatus compared with whipping. Journal of Food Science, 62(2), 377-381.

Brand-Williams, W., Cuvelier, M.E., Berset, C. 1995. Use of a free radical method to evaluate antioxidant activity. LWT-Food Science and Technology, 28(1), 25-30.

Çakmak, H. 2020. Evaluation of foam-mat drying behavior of crab apple (Malus floribunda) fruit juice and powder quality. Gida/ The Journal of Food, 45(3), 530-543.

Courraud, J., Berger, J., Cristol, J.P., Avallone, S. 2013. Stability and bioaccessibility of different forms of carotenoids and vitamin A during in vitro digestion. Food Chemistry, 136, 871-877.

Cozma, A., Petcu, M., Velicevici, G., Cretescu, I. 2015. Evaluation of physicochemical characteristics on commercially available carrot juice and carrot juice mixed with other fruit. Journal of Horticulture, Forestry and Biotechnology, 19(1), 158-161.

Demir, N., Bahçeci, K.S., Acar, J. 2007. The effect of processing method on the characteristics of carrot juice. Journal of Food Quality, 30(5), 813-822.

Dickinson, E. 2017. Biopolymer-based particles as stabilizing agents for emulsions and foams. Food Hydrocolloids, 68, 219-231.

Foegeding, E.A., Davis, J.P. 2011. Food protein functionality: A comprehensive approach. Food Hydrocolloids, 25(8), 1853-1864.

Gamboa-Santos, J., Montilla, A., Soria, A.C., Villamiel, M. 2012. Effects of conventional and ultrasound blanching on enzyme inactivation and carbohydrate content of carrots. European Food Research and Technology, 234(6), 1071-1079.

Gumus, C.E., Decker, E.A., McClements, D.J. 2017. Formation and stability of $\omega-3$ oil emulsion-based delivery systems using plant proteins as emulsifiers: Lentil, pea, and faba bean proteins. Food Biophysics, 12(2), 186-197.

Kilian, J., Aparecida Fernandes, I., Luize Lupatini Menegotto, A., Steffens, C., Abirached, C., Steffens, J., Valduga, E. 2020. Interfacial and emulsifying properties of whey protein concentrate by ultrafiltration. Food Science and Technology International, 26(8), 657 665.

Klein, C.S., Rodriguez-Concepcion, M. 2015. Carotenoids in carrot. In: Pigments in Fruits and Vegetables. Chen C., Springer.

Kudra, T., Ratti, C. 2006. Foam-mat drying: Energy and cost analyses. Canadian Biosystems Engineering, 48 (3), 27-32. 
Leja, M., Kamińska, I., Kramer, M., Maksylewicz-Kaul, A., Kammerer, D., Carle, R., Baranski, R. 2013. The content of phenolic compounds and radical scavenging activity varies with carrot origin and root color. Plant Foods for Human Nutrition, 68(2), 163 170.

Liao, H., Sun, Y., Ni, Y., Liao, X., Hu, X., Wu, J., Chen, F. 2007. The effect of enzymatic mash treatment, pressing, centrifugation, homogenization, deaeration, sterilization and storage on carrot juice. Journal of Food Process Engineering, 30(4), 421-435.

Ma, T., Tian, C., Luo, J., Zhou, R., Sun, X., Ma, J. 2013. Influence of technical processing units on polyphenols and antioxidant capacity of carrot (Daucus carrot L.) juice. Food Chemistry, 141(3), 1637-1644.

Mapelli-Brahm, P., Corte-Real, J., Meléndez-Martínez, A.J., Bohn, T. 2017. Bioaccessibility of phytoene and phytofluene is superior to other carotenoids from selected fruit and vegetable juices. Food Chemistry, 229, 304-311.

McClements, D.J. 2005. Food Emulsions: Principles, Practices, and Techniques, CRC Press, Boca Raton.

Murray, B.S., Durga, K., Yusoff, A., Stoyanov, S.D. 2011. Stabilization of foams and emulsions by mixtures of surface active food-grade particles and proteins. Food Hydrocolloids, 25(4), 627-638.

Nowacka, M., Wedzik, M. 2016. Effect of ultrasound treatment on microstructure, colour and carotenoid content in fresh and dried carrot tissue. Applied Acoustics, 103, 163-171.

Pelegrine, D.H.G., Gasparetto, C.A. 2005. Whey proteins solubility as function of temperature and pH. LWT-Food Science and Technology, 38(1), 77-80.

Pernell, C.W., Foegeding, E.A., Luck, P.J., Davis, J.P. 2002. Properties of whey and egg white protein foams. Colloids and Surfaces A: Physicochemical and Engineering Aspects, 204(1-3), 9-21.

Rodriguez-Amaya, D.B. 2001. A guide to carotenoid analysis in foods. ILSI Press, Washington.

Sadahira, M.S., Rodrigues, M.I., Akhtar, M., Murray, B.S., Netto, F.M. 2016. Effect of egg white protein-pectin electrostatic interactions in a high sugar content system on foaming and foam rheological properties. Food Hydrocolloids, 58, 1-10.

Sangamithra, A., Venkatachalam, S., John, S.G., Kuppuswamy, K. 2015. Foam mat drying of food materials: A review. Journal of Food Processing and Preservation, 39(6), 31653174.

Schultz, A.K., Barrett, D.M., Dungan, S.R. 2014. Effect of acidification on carrot (Daucus carota) juice cloud stability. Journal of Agricultural and Food Chemistry, 62(47), 11528 11535.

Sharma, H.K., Kaur, J., Sarkar, B.C., Singh, C., Singh, B. 2009. Effect of pretreatment conditions on physicochemical parameters of carrot juice. International Journal of Food Science \& Technology, 44(1), 1-9.

Silva, A.C.B., dos Santos Schuquel, L.C., da Silva, C.O., Pascoal, G.B. 2016. Nutritional and physicochemical quality in fresh and fresh-cut carrot (Daucus carota 1.). Demetra: Food, Nutrition \& Health, 11(2), 355-367.

Singleton, V.L., Rossi, J.A. 1965. Colorimetry of total phenolics with phosphomolybdicphosphotungstic acid reagents. American journal of Enology and Viticulture, 16(3), 144158. 
Stahl, W., Sies, H. 1999. Carotenoids: Occurrence, Biochemical Activities, and Bioavailability, In: Antioxidant Food Supplements in Human Health. Packer L., Hiramatsu M., Yoshikawa T, Academic Press.

Ustunol, Z. 2015. Applied Food Protein Chemistry, John Wiley \& Sons, Ltd.

Walsh, G. 2014. Proteins Biochemistry and Biotechnology. John Wiley \& Sons, Ltd.

Yang, X., Foegeding, E.A. 2010. Effects of sucrose on egg white protein and whey protein isolate foams: factors determining properties of wet and dry foams (cakes). Food Hydrocolloids, 24(2-3), 227-238.

Yang, X., Foegeding, E.A. 2011. The stability and physical properties of egg white and whey protein foams explained based on microstructure and interfacial properties. Food Hydrocolloids, 25(7), 1687-1701.

Ye, A., Flanagan, J., Singh, H. 2006. Formation of stable nanoparticles via electrostatic complexation between sodium caseinate and gum arabic. Biopolymers: Original Research on Biomolecules, 82(2), 121-133.

Yilmaz, B., Cakmak, H., Tavman, S. 2019. Ultrasonic pretreatment of carrot slices: Effects of sonication source on drying kinetics and product quality. Anais da Academia Brasileira de Ciências, 91(3), e20180447. 